\title{
Continuous Daily Dosing of Sunitinib in Patients with Metastatic Renal Cell Cancer
}

\author{
Lauren Harshman Sandy Srinivas
}

Stanford University School of Medicine, USA

In this issue of ONKOLOGIE, Kahl and colleagues describe their experience with continuous daily dosing (CDD) of sunitinib [1]. Sunitinib is an orally available multi-targeted tyrosine kinase inhibitor (TKI) whose receptor (R) targets include VEGFR 1-3, PDGFR, c-KIT, FLT-3 and RET [2]. It is currently FDA-approved for the treatment of advanced renal cell carcinoma (RCC) and refractory gastrointestinal stromal tumor (GIST). The FDA-approved dose in advanced RCC and GIST is $50 \mathrm{mg}$ orally daily with a 4 weeks on and 2 weeks off schedule (4/2). This intermittent dosing was based on a large randomized controlled trial which compared sunitinib to the standard therapy at the time, interferon- $\alpha$ (IFN- $\alpha$ ) and demonstrated that sunitinib induced higher response rates and improved progression-free survival (PFS) over IFN- $\alpha$ [3]. Recently an updated survival analysis of that study has shown that sunitinib improves overall survival by 4.6 months compared to IFN- $\alpha[4]$.

The half life of sunitinib and its active metabolite, SU 012662 , is 60 and $105 \mathrm{~h}$, respectively [5]. It has been studied in different weekly dosing schedules including $2 / 1,2 / 2$, and $4 / 2$ [6-8]. The rationale behind the interrupted dose is based on its prolonged half life and concern for accumulation of the active metabolite with continuous dosing. In preclinical studies, the $50 \mathrm{mg}$ daily dosing produced plasma concentrations above $50 \mathrm{ng} / \mathrm{ml}$, which was the level required to inhibit both the VEGF and PDGF receptors [5]. In clinical studies, the most common dose-limiting toxicities included fatigue, lethargy, and asthenia. Fatigue generally occurred 2 weeks after dosing and disappeared during the 2 week rest period [5].

While the intermittent dosing may allow for less toxicity, it may not be beneficial in all diseases as the rest period may allow time for disease progression. A prime example of an inappropriate disease for intermittent dosing was Fiedler and colleagues' phase I study evaluating sunitinib in acute myelogenous leukemia (AML) patients [9]. Responses in the inter- rupted schedule cohort were short-lived and most patients experienced an increase in blast count during the rest period. These results suggest a need for alternate dosing in rapidly growing tumors.

Continuous lower dose sunitinib has been investigated in metastatic RCC: 107 metastatic RCC patients with progressive disease on prior cytokine therapy were treated with sunitinib at $37.5 \mathrm{mg}$ daily without interruption [10]. Patients were escalated to $50 \mathrm{mg}$ if they experienced no dose-limiting toxicities. Overall, responses were slightly lower compared to the $50 \mathrm{mg}, 4 / 2$ intermittent dosing schedule, but the continuous dosing regimen was well tolerated and PFS was similarly encouraging at 8.2 months. Given these promising results, a randomized trial comparing continuous dosing to the interrupted/intermittent $4 / 2$ regimen is currently accruing patients with metastatic RCC (www.clinicaltrials.gov). Further support of a lack of concentration rebound was seen in a similar study in GIST patients where CDD of sunitinib $37.5 \mathrm{mg}$ was deemed safe and effective [11]. Sunitinib CDD achieved constant drug exposure with no unexpected accumulation. Furthermore, a persistent pharmacodynamic effect was seen without the concentration rebound observed during off-treatment periods with intermittent dosing.

Kahl and colleagues report their experience with 4 metastatic RCC patients who had radiographic evidence of disease progression on sunitinib $50 \mathrm{mg}$ daily on a $4 / 2$ schedule, who were then dose escalated to a continuous daily dosing schedule [1]. 3 patients had stabilization of disease for 4-12 months and experienced only mild toxicity.

It is intriguing to speculate on the reason for response with continuous daily dosing of sunitinib. Are higher levels of drug needed to sustain continued VEGFR inhibition [12]? Does the continuous dosing overcome resistance that may develop during the rest period on the intermittent schedule? Does it prevent rebound growth? This rebound effect has been ob-

\begin{tabular}{|c|c|}
\hline KARGER & (C) 2008 S. Karger GmbH, Freiburg \\
\hline $\begin{array}{l}\text { Fax +49 } 7614520714 \\
\text { E-mail Information@Karger.de } \\
\text { www.karger.com }\end{array}$ & $\begin{array}{l}\text { Accessible online at: } \\
\text { www.karger.com/onk }\end{array}$ \\
\hline
\end{tabular}


served anecdotally after so-called 'drug holidays' when these TKIs are stopped. But the consistent re-growth and subsequent resistance to the same agent and dose on re-initiation has confirmed that prolonged drug holidays are not an option with these agents.

Full-dose CDD sunitinib was relatively well-tolerated in this study with only mild (CTC grade 1-2) toxicities of hypertonia, weakness, and diarrhea. Outside of the likely mucositis-related diarrhea, the more common side effects of intermittent dosing sunitinib including hypertension, fatigue, hypothyroidism, and hand-foot syndrome were not seen in this small series.

Kahl and colleagues' successful experience with continuous dosing sunitinib as an alternative treatment after progressive disease is promising and deserves further investigation to prove it equivalent or superior to other second-line agents such as sorafenib. To this end, the results of the accruing sunitinib $37.5 \mathrm{mg}$ continuous daily dosing trial should be revealing.

\section{References}

1 Kahl C HI, Freund M, Casper J: Continuous therapy of sunitinib in patients with metastatic renal cell carcinoma. Onkologie 2008;31:485.

2 Mendel DB, Laird AD, Xin X, et al.: In vivo antitumor activity of SU11248, a novel tyrosine kinase inhibitor targeting vascular endothelial growth factor and platelet-derived growth factor receptors: determination of a pharmacokinetic/pharmacodynamic relationship. Clin Cancer Res 2003;9:327-37.

3 Motzer RJ, Hutson TE, Tomczak P, et al.: Sunitinib versus interferon alfa in metastatic renal-cell carcinoma. N Engl J Med 2007;356:115-24.

4 Figlin RA HT, Tomczak P, Michaelson MD, Bukowski RM, Negrier S, Huang X, Kim ST, Chen I, Motzer RJ: Overall survival with sunitinib versus interferon (IFN)-alfa as first-line treatment of metastatic renal cell carcinoma (mRCC). ASCO Annual Meeting Proceedings 2008; Abstr 5024.

5 Faivre S, Delbaldo C, Vera K, et al.: Safety, pharmacokinetic, and antitumor activity of SU11248, a novel oral multitarget tyrosine kinase inhibitor, in patients with cancer. J Clin Oncol 2006;24:25-35.
6 Chow LQ, Eckhardt SG: Sunitinib: from rational design to clinical efficacy. J Clin Oncol 2007;25: 884-96.

7 Raymond E FS, Vera K, Delbaldo C, Robert C, Spatz A, Bello C, Brega N, Scigalla P, Armand JP: Final results of a phase I and pharmacokinetic study of SU11248, a novel multi-target tyrosine kinase inhibitor, in patients with advanced cancers. Proc Am Soc Clin Oncol 2003;22:Abstr 769.

8 Rosen L MM, Long J, Wittner J, Brown J, Martino AM, Bello CL, Walter S, Scigalla P, Zhu J: Phase I trial of SU011248, a novel tyrosine kinase inhibitor in advanced solid tumors. Proc Am Soc Clin Oncol 2003;22:Abstr 765.

$\checkmark 9$ Fiedler W, Serve H, Dohner H, et al.: A phase 1 study of SU11248 in the treatment of patients with refractory or resistant acute myeloid leukemia (AML) or not amenable to conventional therapy for the disease. Blood 2005;105:986-93.
10 Srinivas SRJ, Gillessen S, Harmenberg U, De Mulder PH, Fountzilas G, Vogelzang N, Peschel C, Flodgren $\mathrm{P}$, Escudier B: Continuous daily administration of sunitinib in patients (pts) with cytokine-refractory metastatic renal cell carcinoma (mRCC): Updated results. J Clin Oncol, ASCO Annual Meeting Proceedings Part I 2007;25:Abstr 5040.

11 George SBJ, Casali PG, Le Cesne A, DePrimo SE, Harmon CS, Law CN, Tassell V, Baum CM, Demetri GD: Continuous daily dosing (CDD) of sunitinib (SU) in pts with advanced GIST: Updated efficacy, safety, PK and pharmacodynamic analysis. J Clin Oncol 2008;26:ASCO Annual Meeting (May 20 suppl):Abstr 10554.

12 Houk BE BC, Michaelson MD, Bukowski RM Redman BG, Hudes GR, Wilding G, Motzer RJ. Exposure-response of sunitinib in metastatic renal cell carcinoma (mRCC): A population pharmacokinetic/pharmacodynamic (PKPD) approach. J Clin Oncol, ASCO Annual Meeting Proceedings Part I 2007;25:Abstr 5027 